\title{
TRAMPAS NO CONVENCIONALES ASOCIADAS CON OFIOLITAS DE LA FAJA SEPTENTRIONAL DE HIDROCARBUROS (LA HABANA-MATANZAS, CUBA)
}

\author{
Eduardo A. Rossello ${ }^{1 *}$; Rolando García-Sánchez ${ }^{2}$ \\ DOI: http://dx.doi.org/10.18273/revbol.v39n3-2017003 @ @ (1)
}

Forma de citar: Rossello, E.A., y García-Sánchez, R. 2017. Trampas no convencionales asociadas con ofiolitas de la faja septentrional de hidrocarburos (la Habana-Matanzas, Cuba). Boletín de Geología, 39(3): 41-54.

\section{RESUMEN}

Las rocas máfico-ultramáficas son muy abundantes en Cuba a lo largo de unos $200 \mathrm{~km}$ del margen septentrional que deben su origen a una corteza oceánica, compuesta por serpentinitas, gabros, diabasas y basaltos conocidos como complejo ofiolítico. Las características geológicas del territorio cubano son el resultado de una historia tectosedimentaria multiepisódica, representada por una serie de secuencias y estructuras relacionadas estrechamente con la evolución del Caribe Occidental. En la Faja Septentrional de Hidrocarburos de Cuba, las ofiolitas intercaladas como escamas tectónicas entre niveles carbonáticos mesozoicos proporcionan en muchos campos buenas condiciones de reservorios y sellos. Las acumulaciones petroleras se encuentran generalmente entre 500 - $800 \mathrm{~m}$ y hasta $3 \mathrm{~km}$ de profundidad con espesores de hasta $400 \mathrm{~m}$ saturados de petróleos con $9^{\circ}$ a $19^{\circ}$ API. Los reservorios son serpentinitas fracturadas, con valores promedio de porosidad en testigo de $5,6 \%$, mientras que por perfilajes alcanza $8,0 \%$, aunque los valores promedios sólo llegan a 1,1\% y las permeabilidades varían entre 0,001 a 21,4 mD. Otros campos se relacionan con escamas tectónicas de cataclasitas de serpentinitas, peridotitas, gabros y diabasas, determinantes de un reservorio de tipo poroso o poroso-fracturado con porosidad en testigos entre $0,2-3,3 \%$ y por registros hasta $9,0 \%$, la permeabilidad se reconoce entre 0,001 $290 \mathrm{mD}$ (como promedio 7,370 mD). También, peridotitas, gabros y diabasas con reservorios de tipo fracturado poroso- fracturado por lixiviación del olivino en gabros olivínicos con porosidades por núcleo de 0,12 - 10,6\% (promedio 3,63\%) y por registros hasta $8,0 \%$. Niveles de serpentinitas alteradas por hidratación con propiedades semejantes a las arcillas constituyen sellos locales. Estos yacimientos pueden considerarse modelos análogos a los aun no completamente explorados de los márgenes Pacíficos del continente sudamericano de Colombia, Perú y Chile que exhiben contextos convergentes con presencia de ofiolitas semejantes.

Palabras clave: Reservorios no-convencionales; hidrocarburos; trampas estructurales; ofiolitas; Cuba.

\section{NON-CONVENTIONAL TRAPS ASSOCIATED WITH OPHIOLITES OF THE NORTHERN HYDROCARBON BELT (HAVANA-MATANZAS, CUBA)}

\begin{abstract}
The geological characteristics of the Cuban territory are the result of a multi-episodic tectosedimentary history, represented by a series of sequences and structures closely related to the evolution of the Western Caribbean. Mafic and ultramafic rocks, mainly serpentinized peridotites, gabbros and basalts, are distributed throughout the northern margin of Cuba ( $200 \mathrm{~km}$ of exposure) and are mostly associated with ophiolitic complexes linked to the evolution of the Carribean plate. The northern hydrocarbon belt comprises oceanic volcano-sedimentary sequences forming a stack of thrust sheets (ophiolites-Mesozoic sedimentary carbonates); such configuration is the responsible for the reservoir and seal conditions of the many hydrocarbon fields in the area. Oil accumulations occur mainly at depths around 500 to $800 \mathrm{~m}$, locally up to $3,000 \mathrm{~m}$, with oil-saturated thicknesses up to $400 \mathrm{~m}$ and $9^{\circ}$ to $19^{\circ}$ API. Reservoirs are mainly fractured serpentinites, with mean log porosity values of $\sim 6 \%$ (and up to $8 \%$ SWC) with permeabilities varying between 0.001 to $21.4 \mathrm{mD}$. Porous to dual porous-fractured reservoirs occur in other fields as tectonic slabs of cataclastic serpentinites, peridotites, gabbros and diabases, with porosities < $3 \%$ (in log) and up to $9 \%$ (SWC) and permeabilities ranging between $0.001-290 \mathrm{mD}(7,400 \mathrm{mD}$ average). The highest porosities in the area are recorded in fractured and weathered peridotites and grabbros, with log-derived porosity values up to $11 \%$ (4\% average) and sidewall core up to $8 \%$. Good quality seals are locally formed by the weathering of serpentinites. New concepts in oil exploration involve the analysis of ophiolitic complexes and related rocks in the Pacific margin as potential promising targets. Thus, the resemblance of these Cuban ophiolitic complexes with their under-explored South American analogs opens a new opportunity for hydrocarbon exploration in the offshore of Colombia, Peru and Chile.
\end{abstract}

Keywords: Non-conventional reservoirs; hydrocarbons; structural traps; ophiolites; Cuba.

${ }^{1}$ CONICET - Universidad de Buenos Aires. FCEN, Buenos Aires, Argentina. (*)ea_rossello@yahoo.com.ar

${ }^{2}$ Departamento de Geociencias, Facultad Ingeniería Civil, Universidad Tecnológica de La Habana, La Habana, Cuba. rjgarcias@civil.cujae.edu.cu 


\section{INTRODUCCIÓN}

El objetivo del presente trabajo es describir el potencial exploratorio y productivo de rocas asociadas a ofiolitas de la Faja Septentrional de Hidrocarburos de Cuba donde constituyen reservorios y sellos de diversos campos intercalados como escamas tectónicas entre niveles carbonáticos mesozoicos. Estas rocas han producido unos 20 millones de barriles de petróleo en varios yacimientos en toda la Provincia Norte Cubana, donde se destacan: Cantel, Boca de Jaruco Bloque Este, Motembo (primer yacimiento de petróleo descubierto en Cuba en 1881), Jarahueca y Guanabo (Cubapetróleo, 2002; Magnier et al., 2004). Las serpentinitas no se consideran en Cuba como un objetivo de primera prioridad por su variabilidad lateral y vertical en las propiedades petrofísicas del reservorio, pero como se encuentran a poca profundidad, generalmente entre 500 -800 m, su explotación resulta rentable económicamente (FIGURA 1).

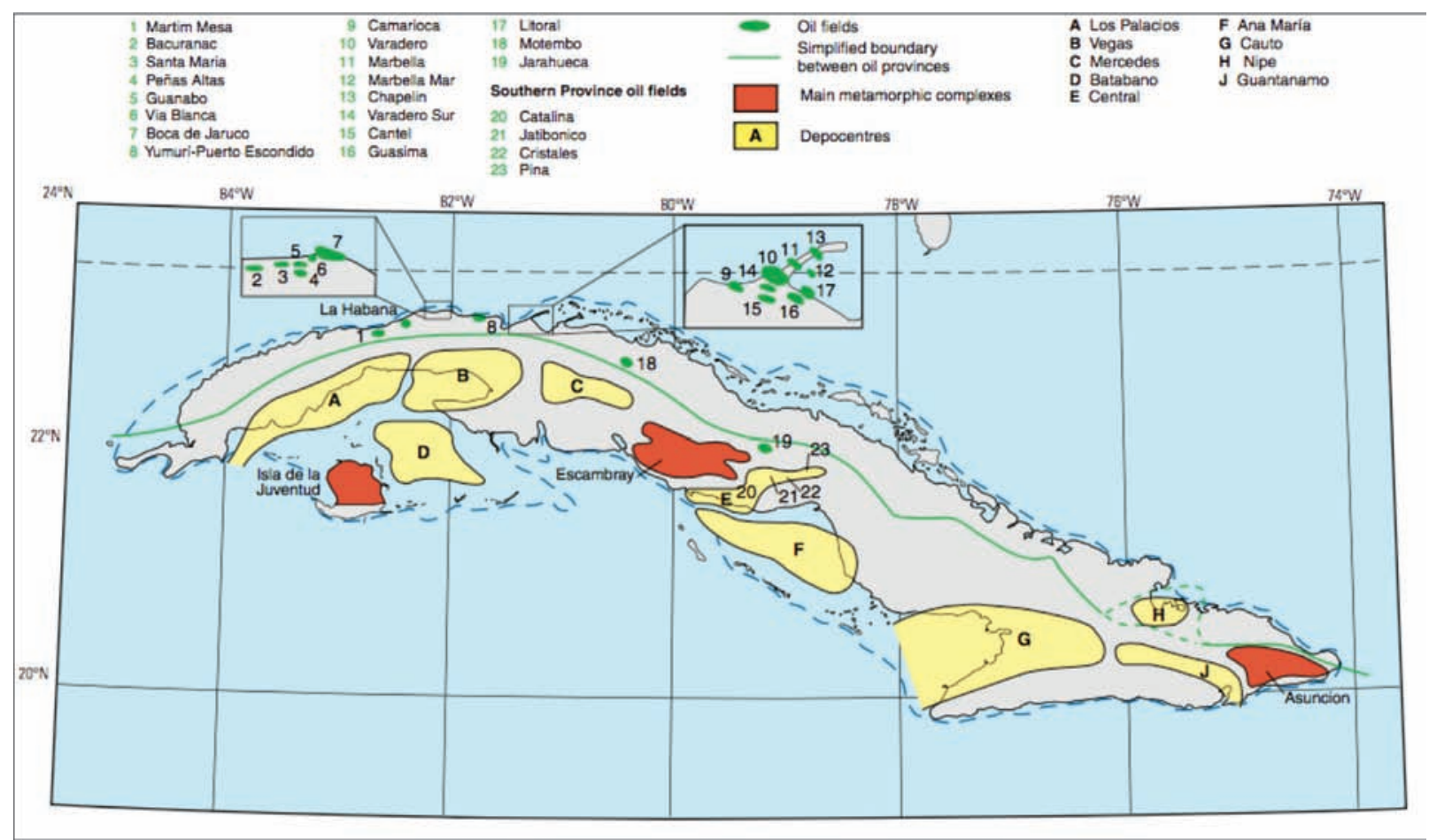

FIGURA 1. Localización de los campos petrolíferos de la Faja Septentrional de Cuba (tomado de Schenk, 2008).

Si bien existen reportes de producción de petróleo en rocas de origen ígneo en el mundo, (Petford y McCaffrey, 2003). Por ejemplo, en diques y filones capa basálticos neógenos de la Cuenca Neuquina de Argentina (Rossello et al., 2002), los gabros de la Península de Santa Elena en Ecuador (Rossello et al., 1999) o en andesitas y tobas carboníferas de la cuenca Junggar (Chen et al., 2016). Sin embargo, son extremadamente escasos en ambientes convergentes con rocas ofiolíticas como las de la Faja petrolífera septentrional de Cuba. Esta región se localiza a lo largo del litoral septentrional de la isla de Cuba, entre La Habana y Matanzas, y se caracteriza por la presencia de unos diez yacimientos conocidos con producción donde las trampas, los reservorios y sus sellos se asocian a gabros serpentinizados jurocretácicos necesarios para definir un sistema petrolífero cuyos fluidos provienen de unidades carbonatadas mesozoicas.

En el presente trabajo se describen las principales características geológicas y petrofísicas de los cuerpos ofiolíticos de Cuba y su potencial en la determinación de un sistema petrolero con la finalidad de poder correlacionarlo con otras regiones análogas, aun subexploradas de contextos geotectónicos semejantes como los presentes en el margen pacifico de Sudamérica. En esta región caracterizada por una convergencia tectónica se conocen sistemas petroleros asociados a prismas acrecionales con rocas básicas de los campos Ancón y Pacoa de la península de Santa Elena del Ecuador (Rossello et al., 1999) y probablemente a escenarios exploratorios aún menos conocidos de Colombia, Perú y Chile. 


\section{MARCO GEOLÓGICO}

Situado en el extremo noroccidental del Mar Caribe el archipiélago cubano es de origen plutónicovolcánico, aunque actualmente constituye un cinturón plegado acrecionado al margen meridional de la Placa Norteamericana (Sykes et al., 1982; Stephan et al., 1990; Iturralde-Vinent et al., 2016). Las características geológicas del territorio cubano son el resultado de una historia tectosedimentaria multiepisódica, representada por una serie de secuencias y estructuras relacionadas estrechamente con la evolución del Caribe Occidental. La presencia de rocas ofiolíticas se reconocen en diversos sectores donde constituyen núcleos de terrenos aflorantes caracterizados por litologías de orígenes oceánicos intercaladas entre asomos de sedimentitas meso-cenozoicas (FIGURA 2).

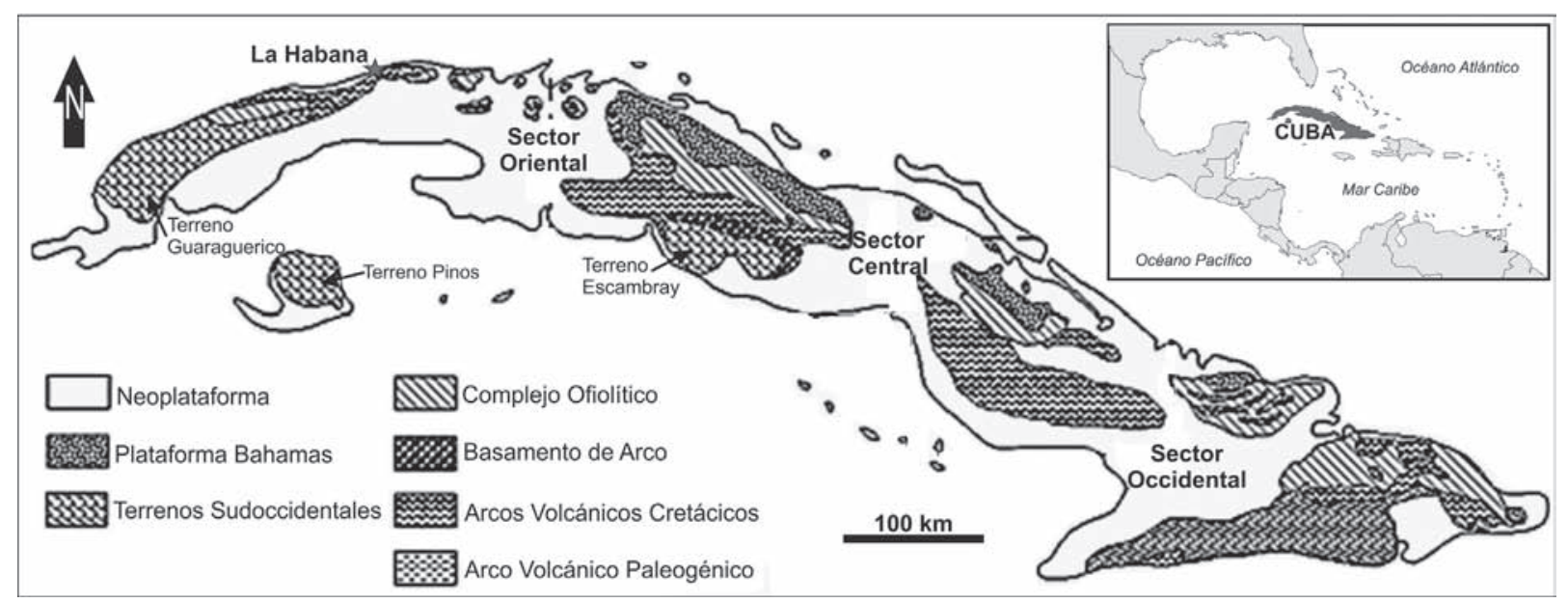

FIGURA 2. Mapa esquemático del territorio cubano, representativo del modelo de su constitución geológica y los afloramientos ofiolíticos (tomado de Iturralde-Vinent, 1996).

El Cinturón Plegado Cubano tuvo su origen vinculado con los procesos de convergencia que se desarrollaron en el Caribe desde comienzos del Cretácico. Hasta el Cretácico Superior se desarrolló conjuntamente con el Cinturón Plegado de las Antillas Mayores, cuando posiblemente comenzó el proceso de colisión entre las secuencias pertenecientes a los terrenos Pinos y Escambray? con el Arco Volcánico AlbianoCampaniano cuando inició la extinción de la actividad volcánica. A partir de la apertura de la Cuenca de Yucatán la evolución del Cinturón Plegado Cubano fue diferente a la del resto de las Grandes Antillas, inclusive Cuba Oriental (García-Casco et al., 2001).

En las secuencias representativas de este período, en Cuba se registra una fuerte actividad de convergencia tectónica responsable de sobrecorrimientos (IturraldeVinent, 1989, 1996, 1998) y el desarrollo de un sistema de cuencas superpuestas (Blanco, 1999). El desarrollo de estas cuencas se relaciona con el proceso de colisión y acreción del Cinturón Plegado Cubano sobre el margen meridional pasivo de la Placa Norteamericana y generalmente se interpreta en dos fases: una primera entre el Campaniano Superior - Maastrichtiano Daniano Inferior, en la que se desarrollaron depósitos que cubrieron la mayor parte del Arco Volcánico Albiano - Campaniano extinto y se caracteriza por rocas clásticas, calizas y margas con deformaciones moderadas, y la segunda fase con semejantes litologías que se desarrolló del Daniano Superior al Eoceno Superior (Iturralde-Vinent, 1994, 1996, 1998; Blanco, 1999). Estos registros están conservados en cuencas en las que dominan areniscas, conglomerados, margas y calizas arcillosas de ambientes marinos profundos y que transicionan lateralmente a calizas de aguas someras. Los detritos de estas cuencas, procedentes de la erosión del arco volcánico y de las ofiolitas, están poco deformados (Iturralde-Vinent, 1996).

Estructuras como fallas normales, inversas o transcurrencias (excluyéndose solo los sobrecorrimientos) existen en toda el área y presentan rumbos predominantes NE-SO, prácticamente perpendiculares al rumbo de emplazamiento del Cinturón Plegado Cubano (FIGURA 3). Estas estructuras afectan sobre todo el substrato plegado, aunque en menor medida pueden aparecer reactivadas en la Neoplataforma (Giunta et al., 2003; Schenk et al., 2005). 


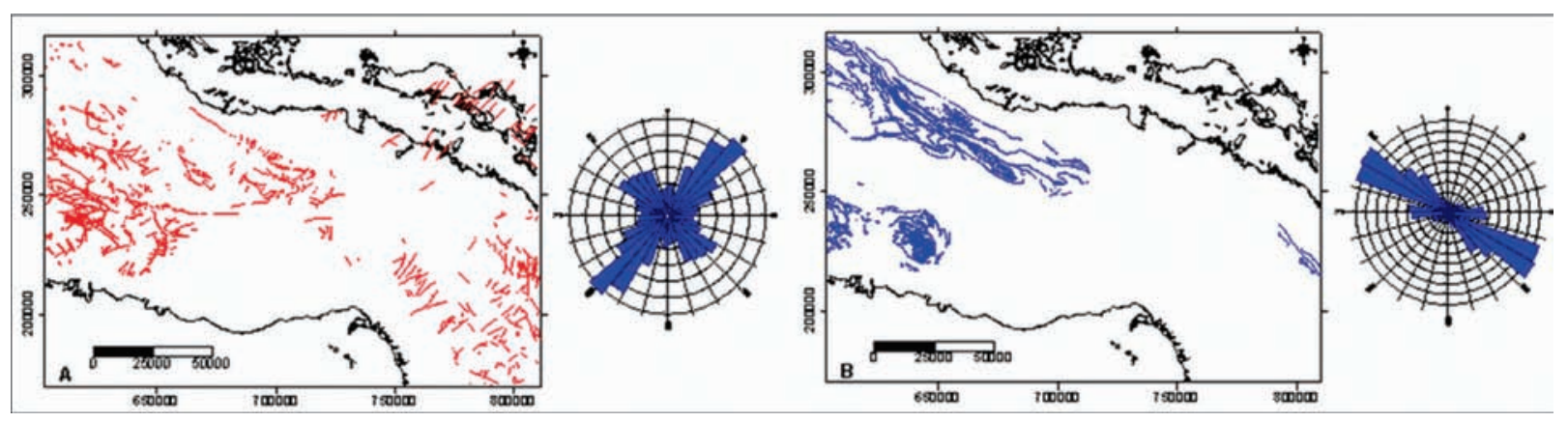

FIGURA 3. Esquemas de las estructuras disyuntivas reportadas en el área de estudio a partir de mapeos. A. Estructuras descritas como fallas (directas, inversas y transcurrentes). B. Estructuras descritas como sobrecorrimientos (tomados de Cruz-Orosa et al., 2005).

El Caribe presenta una gran diversidad geológica relacionada con una evolución tectosedimentaria multiepisódica, que aún en muchos aspectos genéticos es objeto de discusión. La placa del Caribe se mueve hacia el este con respecto a las placas Norteamericana y Suramericana, con una velocidad de 1 a $2 \mathrm{~cm} /$ año (Mann, 1999; Lundgre y Russo, 1996). Los modelos propuestos para explicar el origen y evolución de la placa caribeña se focalizan en el origen de la litosfera oceánica que hoy conforma la Placa del Caribe, pues este aspecto es explicado bajo hipótesis diferentes.

La hipótesis del Caribe Autóctono plantea la generación de la litosfera oceánica del Caribe entre las placas Norteamericana y Suramericana luego de la ruptura de Pangea (Iturralde-Vinent, 1994, 1996; Meschede y Frisch, 1998; Giunta et al., 2003; James, 2006, 2009). Estos modelos “Autóctonos” asumen un origen atlántico para la Placa del Caribe, por lo que pueden caracterizarse como estáticos, pues la cinemática de las placas adyacentes (Norteamericana, Suramericana y Farallón) controlaría sus márgenes (Lázaro-Calisalvo, 2004). Los límites septentrional y meridional tendrían componente transcurrentes, mientras que hacia el oriente y occidente serían como los actuales, zonas de subducción donde se consumirían litósferas oceánicas del Atlántico y del Pacífico respectivamente.

La hipótesis del Caribe Alóctono propone un origen pacífico de la litosfera caribeña (Lapierre et al., 1997; Iturralde-Vinent, 1998; Mann, 1999; Kerr et al., 1999). Según este grupo de modelos, la divergencia mesozoica entre Norteamérica y Sudamérica creó una cuenca oceánica interamericana identificada como el Protocaribe (de origen atlántico). Actualmente, estos elementos están desaparecidos por subducción bajo la placa del Caribe, cuyo origen Jurásico se situaría en el Pacífico (Placa Farallón). Los modelos que proponen desde la década de los 80 `s e inicio de los 90 `s sobre el origen pacífico de la Placa del Caribe fueron extensamente aceptados, con el predominio de algunos que hoy en día ya pueden considerarse como clásicos (Pindell y Dewey, 1982; Pindell, 1994; Ross y Scotese, 1988; Pindell y Barret, 1990).

Sin embargo, durante la segunda mitad de los 90 s, se realizaron trabajos que evidenciaron incompatibilidad de los modelos existentes con la constitución geológica de Cuba (Iturralde-Vinent, 1994, 1996; Proenza, 1998; Blanco, 1999) y un número importante de investigaciones que han contribuido a aumentar el grado de conocimiento geológico de Cuba y de la región del Caribe (James, 2006, 2009). Como resultado de estos avances se logró la creación de modelos bastante completos que han resuelto una buena parte de las contradicciones antes referidas y han logrado integrar las particularidades geológicas de Cuba con los modelos evolutivos del Caribe (Iturralde-Vinent, 1998; Kerr et al., 1999).

Los sobrecorrimientos característicos de la conformación regional de Cuba describen rumbos predominantes NO$\mathrm{SE}$, asociadas al Sistema Cubano que tiene su origen relacionado con los procesos de colisión y acreción del Cinturón Plegado Cubano sobre el margen meridional de la Placa Norteamericana (Iturralde-Vinent, 1996). Estas estructuras aparecen fundamentalmente hacia el margen septentrional de la isla, donde afloran las secuencias de la Plataforma de Bahamas y del Complejo Ofiolítico (Iturralde-Vinent, 1998).

La dirección de la colisión y emplazamiento del Cinturón Plegado Cubano sobre el margen norteamericano fue sub-latitudinal, de sur a norte. El movimiento y avance del frente de colisión fue diferenciado según bloques que fueron separados entre sí por un sistema de fallas rumbo deslizantes de dirección predominante SW-NE (FIGURA 3), que permitieron la rotación y 
reacomodo horizontal y vertical de los bloques según las proporciones del avance generado, la forma $\mathrm{y}$ dimensiones de las estructuras preexistentes en el margen de la Placa Norteamericana.

\section{LOS COMPLEJOS OFIOLÍTICOS DE CUBA}

En Cuba las rocas máfico-ultramáficas son muy abundantes y juegan un papel fundamental en la constitución geológica del territorio. Las ofiolitas se presentan discontinuamente en la mitad septentrional de la isla en decenas de afloramientos desde Cajálbana (Pinar del Río), al occidente, hasta Baracoa la provincia de Holguín (zona oriental) con una extensión de unos $1000 \mathrm{~km}$ de largo y varias decenas de $\mathrm{km}$ de ancho (FIGURA 4). En general, presentan una estructura muy compleja relacionada con las secuencias volcánicas y del margen norteamericano originada por el emplazamiento tectónico de obducción desde el Cretácico tardío al Eoceno tardío (Pszczolkowski, 1999; Iturralde-Vinent et al., 2016). Exhiben deformaciones muy variadas en superficie tanto como fajas estrechas muy deformadas dúctil y frágilmente (FIGURA 5), o bien como mantos o escamas tectónicas con diversas potencias deca a hectométricas. En la región de Las Villas se reconocen fajas estrechas que aparecen en los planos de las fallas que limitan las zonas plegadas del norte, así como entre planos de fallas inversas; mientras que en Camagüey aparecen conformando mantos tectónicos con su estructura interna bastante bien preservada (IturraldeVinent, 1998). En estos sectores sobreyacen las secuencias de la Plataforma de Bahamas y cubiertas de la misma forma por las rocas volcánicas del Cretácico (Iturralde-Vinent, 1998).

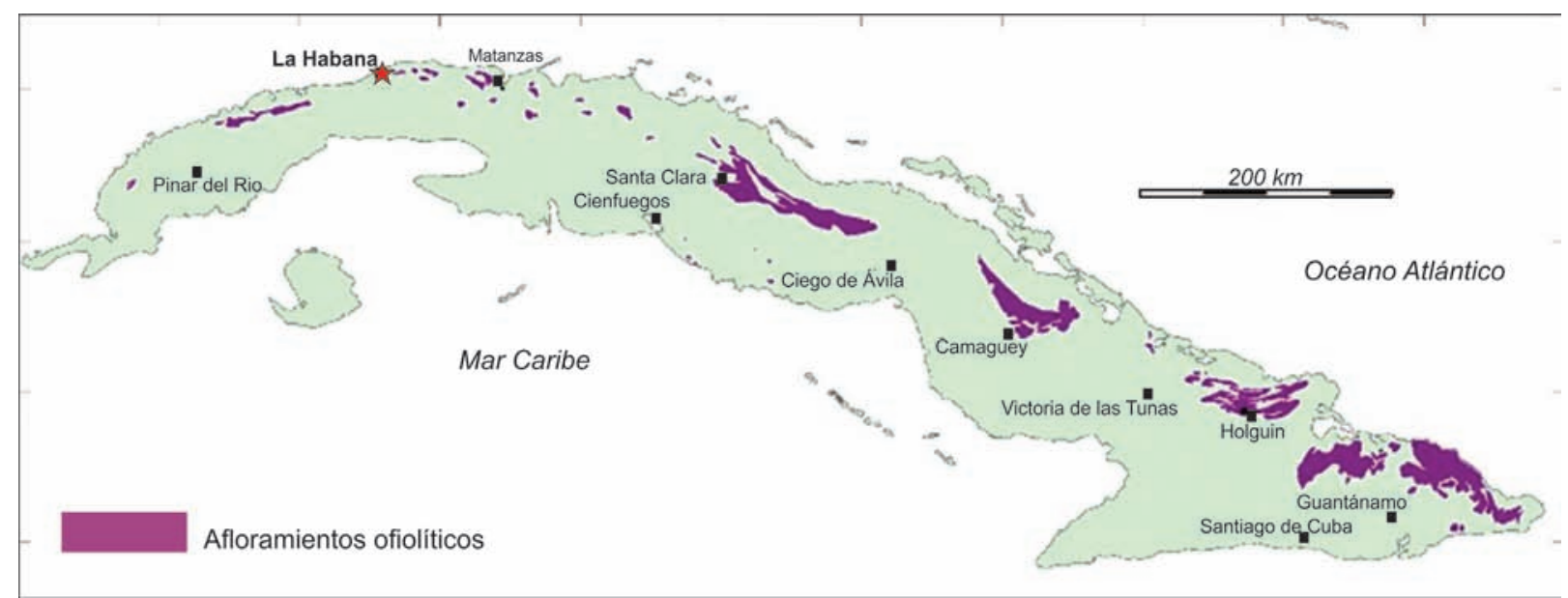

FIGURA 4. Principales afloramientos de las rocas máfico-ultramáficas de Cuba (tomado de Iturralde-Vinent et al., 2016).

El origen de estas rocas se supone relacionado con el desarrollo de una zona de retroarco marginal, contemporánea con la actividad volcánica del Cretácico (Iturralde-Vinent, 1996, 1998; Proenza, 1998; Blanco, 1999). Sin embargo, las dataciones $\mathrm{K}$-Ar que han sido realizadas le infieren edades que oscilan entre 50 y $160 \mathrm{Ma}$ (Iturralde-Vinent, 1998) que confirman las dificultades en sus correlaciones. Por lo tanto, el emplazamiento de estas rocas se estima que comenzó a finales del Cretácico tardío (Campaniano - Maastrichtiano) y concluyen con los principales movimientos durante el Eoceno tardío coetáneamente con el proceso de colisión y acreción del Cinturón Plegado Cubano sobre el margen meridional pasivo de la Placa Norteamericana (Blanco, 1999). Aun así, la edad del emplazamiento de las ofiolitas es un problema mucho más complejo y pendiente de resolver a nivel de detalle, por cuanto sólo se puede precisar a partir de las relaciones estructurales observadas en el campo.

Según Millán (1996) dentro de estas ofiolitas se incluyen harzburgitas y dunitas serpentinizadas (FIGURA 5), gabros bandeados e isotrópicos, basaltos y hialoclastitas (basaltos tholeíticos y de retroarco, localmente con composiciones boniníticas) superpuestas por sedimentos oceánicos del Jurásico tardío (Tithoniano) a Cretácico tardío (Coniaciano y más joven). Los diques estratificados y los gabros isotrópicos son raros (Iturralde-Vinent, 1996). Los datos petrológicos, geoquímicos y geocronológicos disponibles sugieren que las ofiolitas cubanas tienen origen de tipos tanto de dorsales medio oceánicas como de zonas de suprasubducción. Sin embargo, la ocurrencia generalizada en las ofiolitas de peridotitas del manto muy refractarias así 
como rocas extrusivas con características geoquímicas de arcos de isla indica que los protolitos de la mayoría de los ofiolitas cubanas se formaron sobre una zona de subducción tanto de antearco y retroarco (Kerr et al., 1999; Proenza et al., 2006; Marchesi et al., 2007; Lázaro et al., 2015).
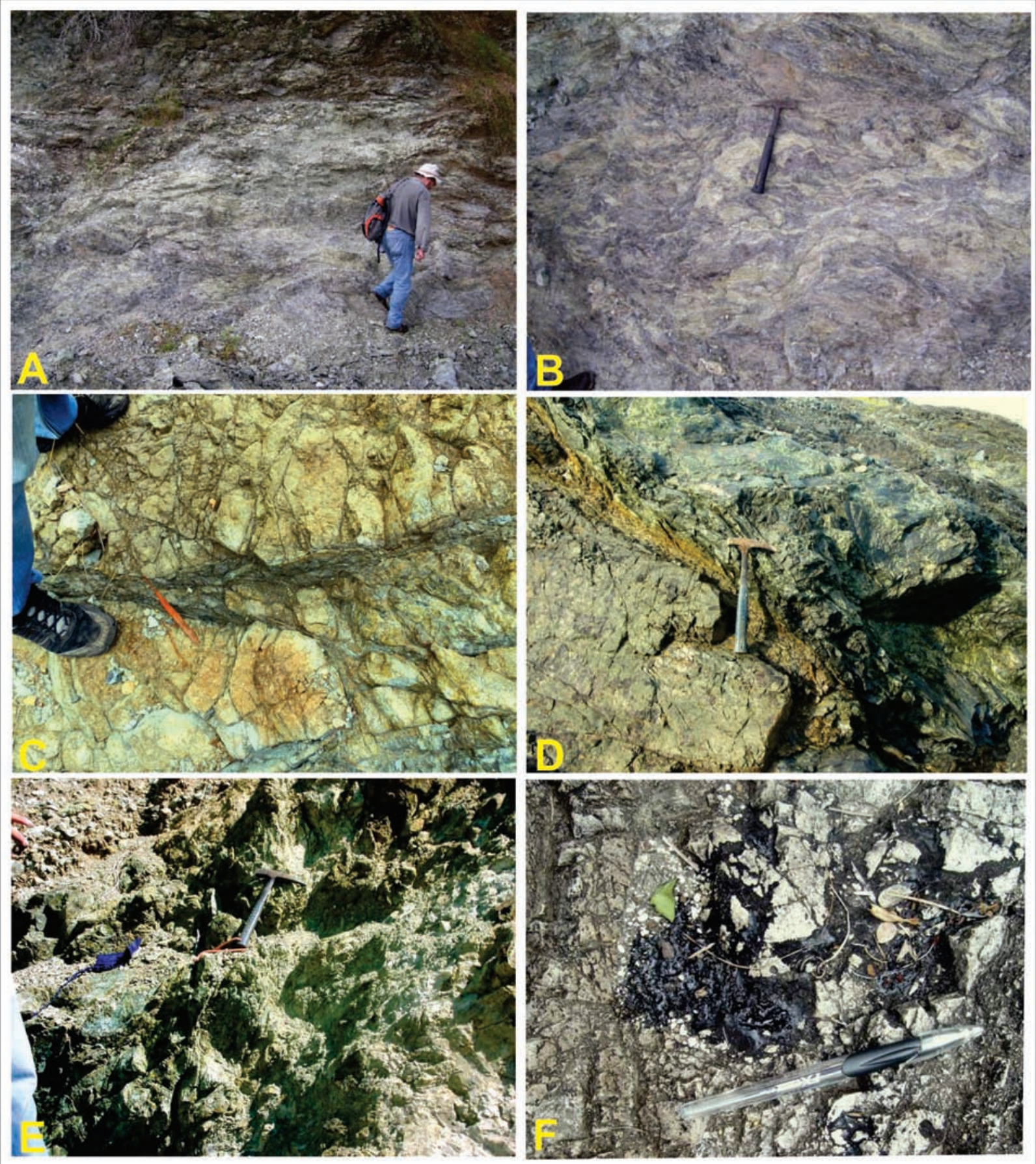

FIGURA 5. Fotografías de algunos ejemplos de afloramientos de ofiolitas serpentinizadas. A. Vista general de serpentinitas planos discontinuos variablemente alterados de una cantera de serpentinita cercana al Campo Martin Mesa (véase localización en FIGURA 1). B. Detalle del anterior. C. Serpentinitas fracturadas en Cantera Guanabacoa. D. Bloques de serpentinitas limitados por fallamientos cataclásticos de una cantera cercana al Campo Martin Mesa. E. Serpentinitas muy fracturadas y con variables grados de alteración. F. Detalle de manifestaciones de petróleo fluyentes en serpentinitas cataclizadas. 
Durante la subducción y la obducción sufrida por Cuba, las ofiolitas fueron desmembradas donde bloques exóticas fallados de la placa Norteamericana y de los arcos cretácicos se incorporaron dentro de los cuerpos ofiolíticos deformados. Estas rocas se encuentran emplazadas a lo largo del territorio cubano, conformando un amplio cinturón que debe su origen a una corteza oceánica, compuesta por serpentinitas, gabros, diabasas, basaltos, conocidos como complejo ofiolítico (FIGURA 5). Según Iturralde-Vinent (1996), un concepto novedoso aplicado a las asociaciones máfico-ultramáficas de Cuba, es la distinción de las mélanges serpentiníticas con bloques de metamorfitas de alta presión, característica de los canales de subducción. De este modo, fajas asociadas de mélanges relacionadas con la subducción contienen bloques de alta presión (alto-P) constituidos por eclogitas, anfibolitas, esquistos azules y rocas de facies de alta presión de esquistos verdes y jadeíta en una matriz serpentinítica. Estas mélanges se formaron en una zona de subducción desde 120 Ma hasta el Cretácico tardío (65 Ma). Mélanges similares con los bloques de alta- presión ocurren como olistolitos dentro de la cuenca de antepaís y como láminas tectónicas dentro del Complejo Escambray (García-Casco et al., 2001; Blanco-Quintero et al., 2011; Cárdenas-Párraga et al., 2012).

\section{LOS RESERVORIOS OFIOLÍTICOS DE CUBA}

En Cuba existen importantes objetivos de interés petrolero costa adentro y costa afuera cercana asociados con litologías ofiolíticas, a pesar de consistir en yacimientos volumétricamente pequeños (ValladaresAmaro et al., 1996). Schenk et al. (2005) estimaron promedios totales de unos 4,6 billones de barriles de petróleo (BBP), un promedio de 9,8 trillones de pies cúbicos (TPC) de gas natural (8,6 TPC de gas asociadodisuelto y 1,2 TPC de gas no asociado), y un promedio total de 0,9 billón de barriles de líquidos de gas natural en las tres regiones actuales productoras de Cuba. Del promedio de 4,6 BBP, alrededor de 0,49 BBP se encuentra en la región del Cinturón Plegado del margen Septentrional de Cuba (FIGURA 6).

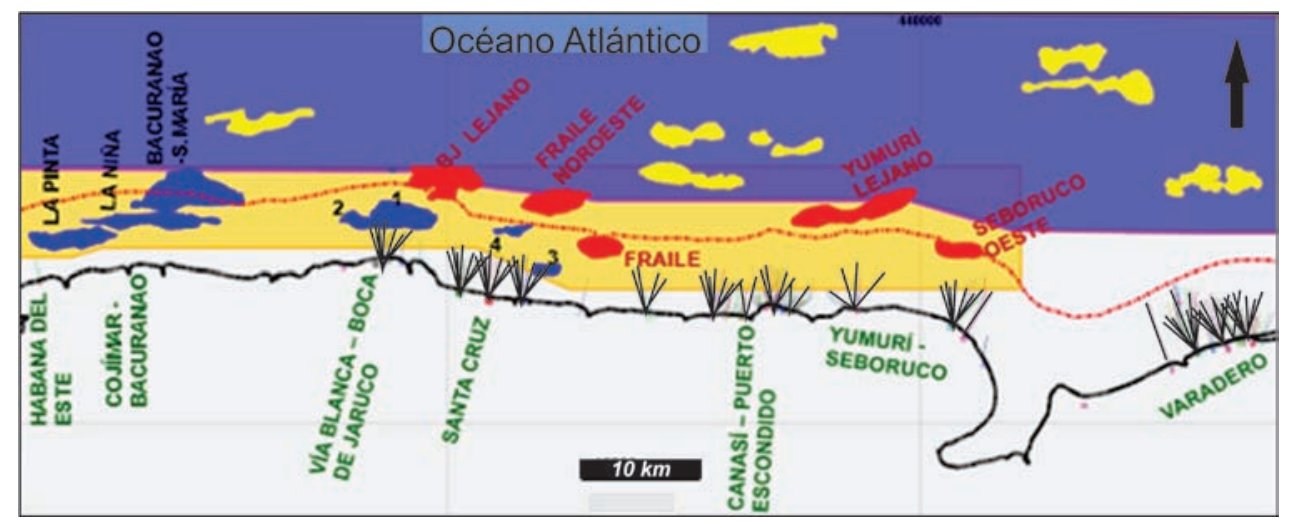

FIGURA 6. Campos, prospectos y leads identificados en la Faja hidrocarburifera Septentrional de Cuba. 1. Bocas del Jaruco Norte (brechas). 2. Bocas del Jaruco Norte Veloz. 3. Santa Cruz Este. 4. Santa Cruz Norte. Línea de puntos: indica un límite horizontal hacia el norte a $500 \mathrm{~m}$ desde la costa. En azul: prospectos identificados cercanos a la costa. En rojo: sectores exploratorios medianamente alejados de la costa. En amarillo: leads más alejados de la costa. Las líneas divergentes indican la proyección de los pozos de producción y/o exploración originados desde la costa (tomado de Cubapetróleo, 2002).

En Cuba, donde el 98\% de la producción nacional de hidrocarburos procede de yacimientos carbonáticos con fracturación natural de crudos pesados y muy pesados (entre $9^{\circ}$ y $16^{\circ} \mathrm{API}$ ), el coeficiente de extracción de los recursos petroleros no pasa del 7 - 9\%, quedándose más del $90 \%$ del petróleo en el subsuelo dentro del yacimiento (tomado de Unión Cuba-Petróleo, Cubapetróleo, 2002).

Los cuerpos de ofiolitas a pesar de no ser tradicionalmente reservorios convencionales por la ausencia de porosidad y permeabilidad primarias significativas presentan en Cuba acumulaciones considerables de petróleo por varias razones, entre las que se destacan: a) La presencia de fallamientos que sirvieron de vías para la migración de los hidrocarburos desde las cocinas constituidas por carbonatos del margen continental infrayacente.

b) Su cercanía a los bordes frontales principales del cabalgamiento o a los bordes intramantos.

c) A la no existencia en cantidades substantivas de materiales secundarios (cementos y/o matriz) que ocluyan los espacios porosos efectivos.

Valladares (1985) describe en los yacimientos cubanos emplazados en ofiolitas las propiedades petrofísicas de los siguientes 4 litotipos: 
- Litotipo 1: Serpentinitas fracturadas, con reservorios de tipo fracturado con valores promedio de porosidad de $5,6 \%$ (determinada en testigo) hasta $8,0 \%$ (medida por carotaje) aunque los valores promedios solo llegan a $1,1 \%$ y las permeabilidades varían entre 0,001 a 21,4 $\mathrm{mD}$.

- Litotipo 2: Cataclasitas de serpentinitas, peridotitas, gabros y diabasas, determinantes de reservorios de tipo poroso o poroso-fracturado cuya porosidad medida en testigos es entre $0,2-3,3 \%$ y por registros hasta $9,0 \%$ y permeabilidades entre 0,001 - $290 \mathrm{mD}$ (como promedio 7,370 mD).

- Litotipo 3: Serpentinitas alteradas (hidratadas), las que adquieren propiedades semejantes a las arcillas, por lo que constituyen sellos locales.

- Litotipo 4: Peridotitas, gabros y diabasas fracturada con reservorios de tipo fracturado poroso fracturado (este último por lixiviación del olivino en gabros olivínicos). Las determinaciones petrofísicas muestran una porosidad por núcleo de 0,12 - 10,6 $\%$ (promedio 3,63\%) y por registros de hasta $8,0 \%$.

Se señala que aunque los litotipos 1,2 y 4 poseen propiedades satisfactorias para constituir reservorios, las mayores producciones de hidrocarburos se relacionan con el litotipo 2.

Como las ofiolitas se encuentra en varios yacimientos, sus características como reservorio se han descrito atendiéndose a su ubicación geológica y geográfica dentro del sector norte de la provincia hidrocarburífera y sus morfologías tectónicas las que se resumen a continuación:

a) Yacimientos cercanos al borde frontal principal de los cabalgamientos, sobre los carbonatos del margen continental, donde se ubican las principales acumulaciones en la provincia petrolífera Septentrional de Cuba, por ejemplo los yacimientos Boca de Jaruco, Cantel, Camarioca, con porosidades entre 9 y 10,5 \% (FIGURA 7).

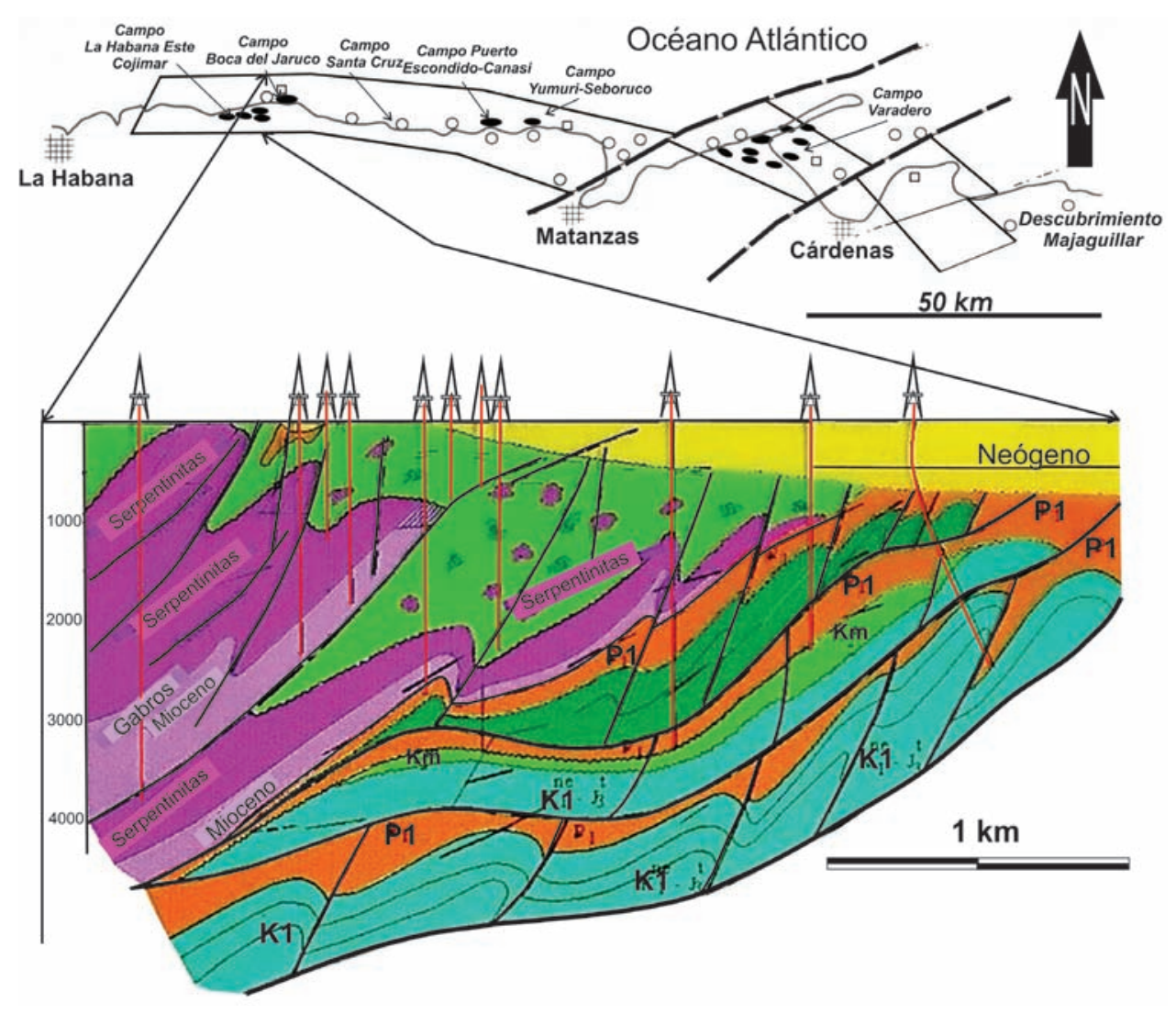

FIGURA 7. Modelo geológico exploratorio para el sector noroccidental del Bloque Tarara-Boca de Jaruco donde se muestran escamas tectónicas de ofiolitas imbricadas dentro de carbonatitas (tomado de Álvarez, 1990). 
b) Yacimientos cercanos a los bordes intramantos, que se ubican al centro y sur del sector, con espesores de hasta $1 \mathrm{~km}$. Sirven de ejemplo las áreas de Bacuranao, Cruz Verde, Brisas, Jarahueca,
Motembo, donde los valores de porosidad alcanzan $5,6 \%$ y una permeabilidad que oscila entre 0,001 a 2,1 mD (FIGURA 8).

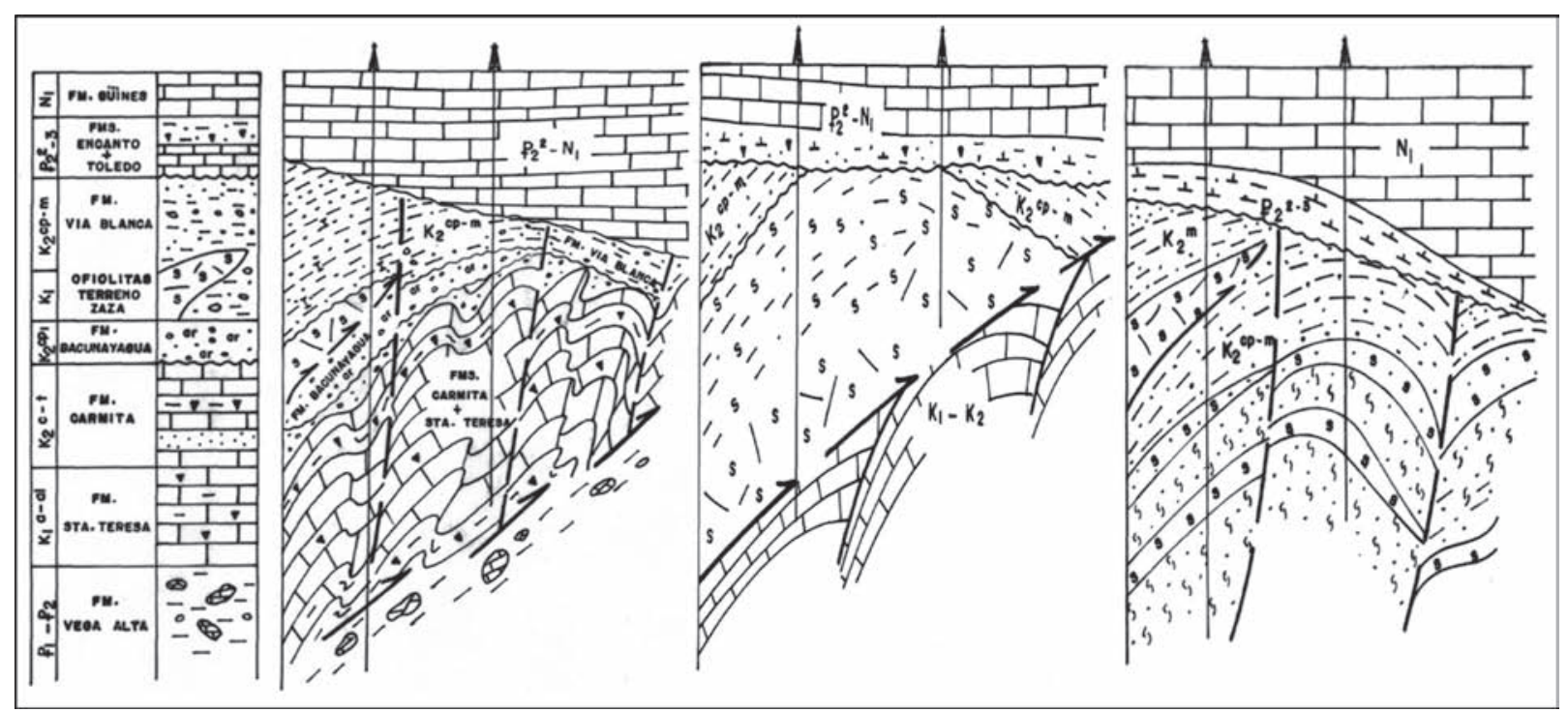

FIGURA 8. Secciones esquemáticas sin escalas de yacimientos de hidrocarburos asociados con ofiolitas (véanse localizaciones en FIGURA 1). Izquierda: Manto de la UTE Placetas con sellos locales del Cretácico Tardío y serpentinitas alteradas. Centro: Bloque Este del Yacimiento Boca de Jaruco donde las serpentinitas alteradas sirven de sello. Derecha: Yacimiento Guanabo.

Las serpentinitas encontradas en los pozos se diferencian facialmente de otras litologías, ya que se agrupan fuera de los rangos permisibles de las litologías convencionales. Así en los cortes se destacan intervalos con litologías mezcladas, formando conglomerados, en otros casos son paquetes de rocas compactas (con alta resistividad) y en terceros casos son serpentinitas trituradas o blandas (baja resistividad), determinándose en cada una su correspondiente dependencia con la porosidad (FIGURA 9).

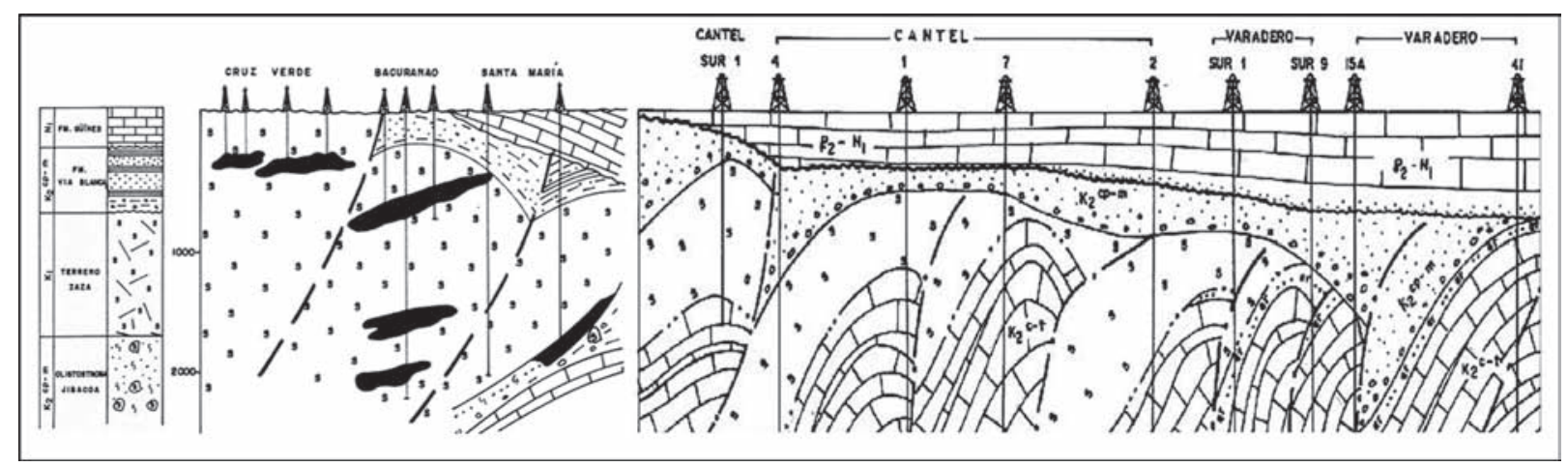

FIGURA 9. Secciones esquemáticas sin escalas de yacimientos de hidrocarburos asociados con ofiolitas (véanse localizaciones en FIGURA 1). Izquierda: Campo Cruz Verde, Bacuranao y Santa María donde las acumulaciones de hidrocarburos están aisladas dentro de volúmenes de ofiolitas. Derecha: Campos Cantel y Varadero donde las acumulaciones de petróleo se disponen en ofiolitas y carbonatos suprayacidos por sedimentitas.

Según Castro (2017), los sectores de serpentinitas compactas con porosidad cero asociados a volúmenes con características de reservorios pueden ser considerados en general como sellos. Mientras que las de tipo fracturado se asocian al reservorio y presentan una mayor resistividad ( $<500 \mathrm{ohm} / \mathrm{m}$ ), con una densidad semejante a las compactas $\left(\sim 2,6609 \mathrm{~g} / \mathrm{cm}^{3}\right)$. Resultados de las investigaciones petrofísicas realizadas por Castro (op. cit) indican que en rocas densas los rangos de porosidad van desde casi cero, hasta mayores de $20 \%$ 
y las porosidades más bajas resultan mejoradas por el incremento de la permeabilidad; en tanto que en las fracturadas los valores de porosidad se muestran entre 12 y $35 \%$, pero a pesar de su alta porosidad la roca es prácticamente impermeable.

Valladares-Amaro et al. (1996) han establecido que el desarrollo de las vías colectoras, los procesos de migración de hidrocarburos desde las rocas carbonatadas y la presencia de sellos en la secuencia ofiolítica, están relacionados con los movimientos ocurridos desde el Maastrichtiano Temprano, en el Eoceno Inferior y hasta la neotectónica Neógena.

En los últimos años, en varios pozos de la región de La Habana se corrieron registros de imágenes FMI, cuyas interpretaciones permitieron identificar varios sistemas de fracturas naturales, que evidencian los efectos de la fuerte actividad tectónica a la que fueron sometidas estas rocas. En este sentido, Brey y Castro (2005) señalan que en todos los casos se observan: a) fracturas conductivas, que podían estas abiertas y favorecer el movimiento o almacenamiento de fluidos, b) fracturas parcialmente abiertas y c) fracturas cerradas por cementación, bien sea por sílice o por carbonato.

El estilo estructural general de los campos con producción en ofiolitas es de tipo imbricado donde láminas o escamas de esta naturaleza se interdigitan tectónicamente con las secuencias carbonáticas conformando paquetes de secuencias multicomposicionales magmáticas y sedimentarias. Los hidrocarburos se encuentran particularmente en sectores cuspidales de láminas que ofrecen sectores discretos con buenas características de reservorios limitadas a su vez por serpentinitas que les hacen de sellos (FIGURA 10).

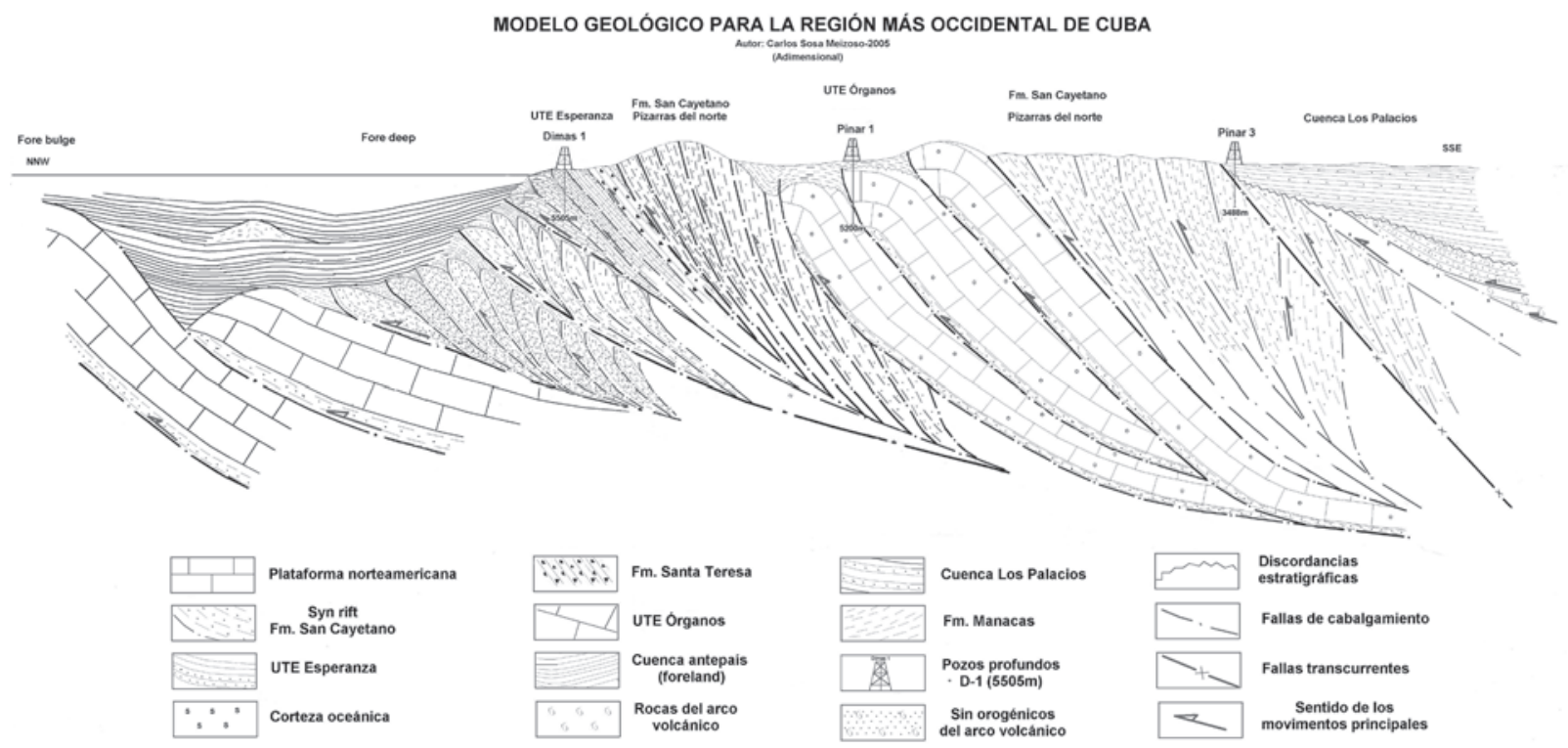

FIGURA 10. Modelo geológico esquematizado para la región más occidental de Cuba (tomado de Sosa-Meizoso y LópezRiviera, 2007).

La Faja Hidrocarburífica Septentrional de Cuba se extiende incluso hacia el mar donde es posible todavía reconocer estructuras que tienen relaciones espaciales diacrónicas con secuencias carbonatadas. De acuerdo con modelos geológicos exploratorios en desarrollo se demuestra que existen mantos de ofiolitas sobrecorridos que presentan sus mejores propiedades como reservorio en las partes de los bordes frontales. Dada la constitución tan complicada de las secciones relacionadas con estos objetivos, se plantean tipos de trampas complejas, en la que intervienen aspectos estructurales y litológicos muy variables.
Un modelo estructural a partir de información de superficie y subsuelo compatible con el marco regional del norte de la placa Caribe asociado con un escenario transcurrente senestral sobre la margen septentrional de Cuba puede ajustarse mejor con la evolución tectónica de esta porción caribeña De este modo, se incorporan a las estructuras tradicionalmente interpretadas otras que exhiben típicos rasgos de flores transpresivas (Sylvester, 1988) a partir de inversiones de fallamientos normales dispuestas subparalelamente al margen isleño (FIGURA 11). 


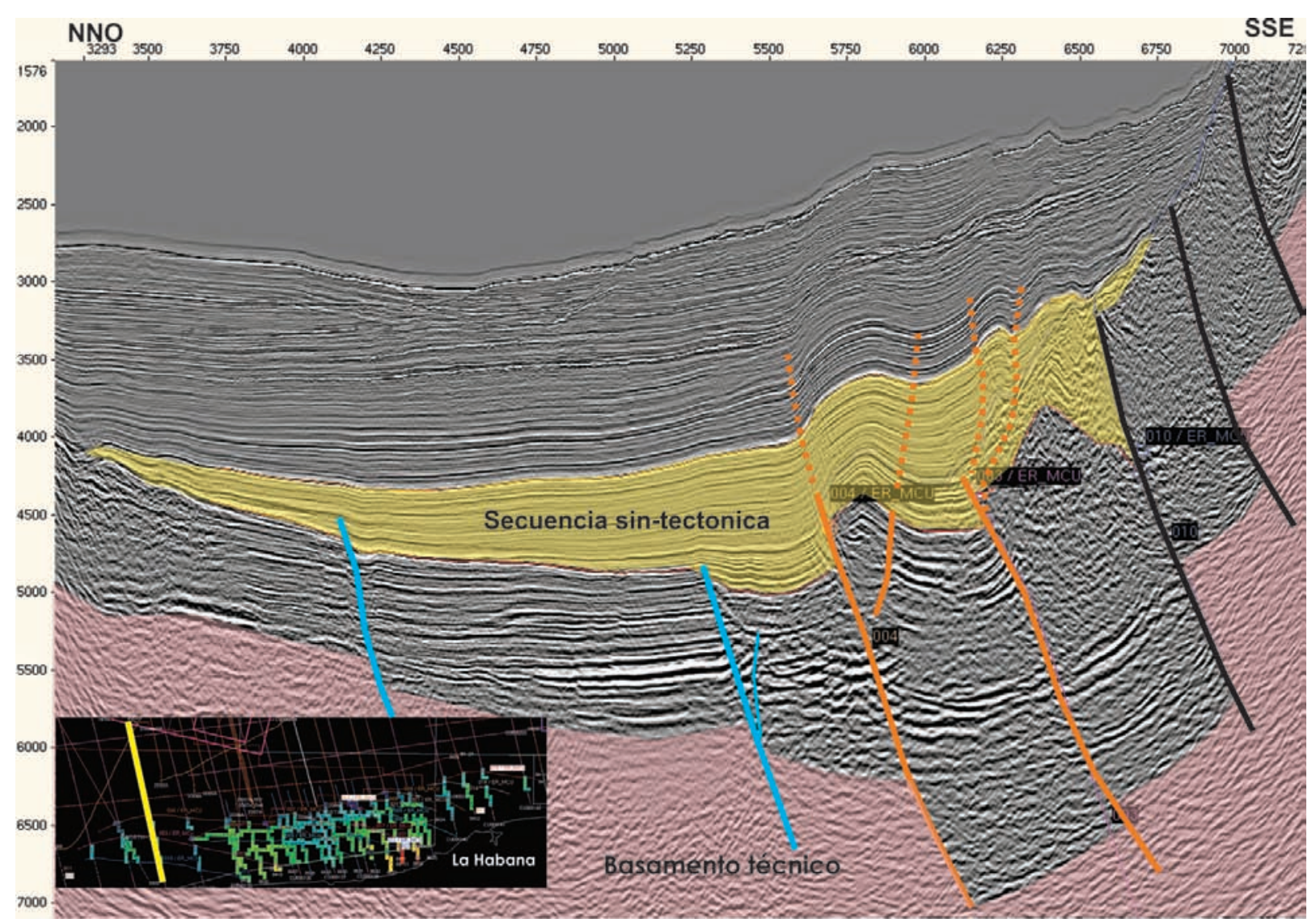

FIGURA 11. Ejemplo de la estructuración de la Faja Septentrional hidrocarburífera de Cuba a partir de una sección sísmica 2D dispuesta aproximadamente NS a partir de la costa al Oeste de La Habana (línea amarilla en el inserto). Trazos azules: fallamientos extensionales tempranos. Trazos negros: fallamientos inversos tardíos. Trazos naranja: fallamientos originalmente extensionales y luego invertidos por transpresión.

\section{CONCLUSIONES}

En Cuba las rocas ofiolíticas son muy abundantes y juegan un papel fundamental en la constitución geológica del territorio. Estas rocas se encuentran conformando un amplio cinturón de unos $200 \mathrm{~km}$ de largo que deben su origen a una corteza oceánica, compuesta por serpentinitas, gabros, diabasas y basaltos, conocidos como complejo ofiolítico.

Las ofiolitas se presentan en decenas de afloramientos desde la provincia occidental de Pinar del Río hasta la provincia oriental de Holguín con deformaciones muy variadas, lo que erróneamente en ocasiones sirvió para pensar que estos extensos cuerpos reflejaban las características de sus homólogos en profundidad. Pero debido a la acción de múltiples eventos tectónicos que las emplazaron sobre el margen continental conjuntamente con carbonatos mesozoicos durante la orogenia cubana desde el Cretácico tardío al Eoceno medio, adquirieron características petrofísicas adecuadas de porosidades y permeabilidades secundarias.
Aunque las litologías ofiolíticas de la Faja Septentrional de Cuba sostienen una serie de campos hidrocarburíferos, no se consideran un objetivo de primera prioridad por su variabilidad en las propiedades del reservorio, pero como se encuentran a poca profundidad (generalmente entre $500-800 \mathrm{~m}$ ), su explotación resulta rentable económicamente. Si bien son explotados por su accesibilidad, suelen tener producciones medias por pozo que pueden rondar de los 1200 a los 4000 BOD y reservas de 30-50 MMBO. Estos cuerpos de rocas presentan acumulaciones de petróleo por varias razones, entre las que se destacan: i) la existencia de fallas postorogénicas que sirvieron de vía para la migración de los hidrocarburos desde los carbonatos del margen continental infrayacentes, ii) la cercanía a los bordes frontales principales del cabalgamiento o a los bordes intramantos y iii) la ausencia del materiales secundarios que ocluyan los espacios porosos efectivos.

La Faja Hidrocarburífera Septentrional de Cuba brinda un excelente ejemplo de yacimientos productores emplazados en litologías ofiolíticas no convencionales 
que pueden asociarse con las típicas de márgenes continentales acrecionales como los presentes en el Pacifico de Sudamérica. De este modo, se constituye en un posible análogo válido para áreas sometidas a exploración vinculadas con márgenes continentales convergentes como los existentes en los confines pacíficos Sudamericanos de Colombia, Ecuador, Perú y Chile.

\section{AGRADECIMIENTOS}

Deseamos agradecer al recordado colega y amigo Carlos Sosa Meisozo por sus valiosos y desinteresados comentarios compartidos sobre la evolución estructural de Cuba. Los arbitrajes de los doctores Oscar López-Gamundí y Gerardo Veroslavsky mejoraron notablemente la claridad del trabajo.

\section{REFERENCIAS}

Álvarez, J. 1990. LEADS Evaluation for the exploration in blocks 6, 7, 9 y 10. Proyect 2132. Stage 1: E-368. CEINPET (La Habana). 30pp.

Blanco, J. 1999. Estratigrafía y paleogeografía de las cuencas superpuestas de Cuba centro-oriental. Tesis Doctoral, ICT, ISMM, Moa, Cuba. 146p.

Blanco-Quintero, I.F., Rojas-Agramonte, Y., GarcíaCasco, A., Kröner, A., Mertz, D.F., Lázaro, C., BlancoMoreno, J., and Renne, P.R. 2011. Timing of subduction and exhumation in a subduction channel: Evidence from slab melts from La Corea Mèlange (eastern Cuba). Lithos, 127(1-2): 86-100.

Brey, D., y Castro, O. 2005. Catálogo de imágenes FMS y FMI en pozos de la Franja Norte de Crudos Pesados de Cuba. I Convención de Ciencias de la Tierra, La Habana, Cuba.

Cárdenas-Párraga, J., García-Casco, A., Harlow, G.E., Blanco-Quintero, I.F., Rojas-Agramonte, Y., and Kröner, A. 2012. Hydrothermal origin and age of jadeitites from Sierra del Convento Mèlange (Eastern Cuba). European Journal of Mineralogy, 24(2): 313-331.

Castro, O. 2017. Evaluación petrofísica de formaciones gasopetrolíferas cubanas. Editorial Centro Nacional de Información Geológica. La Habana, 150p.

Chen, Z., Wang, X., Zha, M., Zhang, Y., Cao, Y., Yang, D., Wu, K., Chen, Y., and Yuan, G. 2016. Characteristics and formation mechanisms of large volcanic rock oil reservoirs: A case study of the Carboniferous rocks in the Kebai fault zone of Junggar Basin, China. AAPG Bulletin, 100(10): 1585-1617.

Cruz-Orosa, I., Blanco-Moreno, J., y Vázquez-Taset, Y.M. 2005. Análisis de la evolución tectónica y paleogeografía de la cuenca Central, Cuba. Consultado el 15 de diciembre de 2016. http://www.monografias. com/trabajos39/evolucion-tectonica-cuba/evoluciontectonica-cuba4.shtml\#concl\#ixzz4ebgywoXh

Cubapetróleo, 2002. The oil industry in Cuba opportunities in the new century. Havana, Cuba. Consultado el 15 de diciembre de 2016. http://www. cupet.cu

García-Casco, A., Torres-Roldán, R.L., Millán, G., Monié, P., and Haissen, F. 2001. High-grade metamorphism and hydrous melting of metapelites in the Pinos terrane (W Cuba): Evidence for crustal thickening and extension in the northern Caribbean collisional belt. Journal of Metamorphic Geology, 19(6): 699-715.

Giunta, G., Beccaluva, L., Coltorti, M., and Siena, F. 2003. The peri-Caribbean ophiolites and implications for the Caribbean Plate evolution. AAPG International Conference, Barcelona, Spain, 1-6.

Iturralde-Vinent, M.A. 1989. Role of ophiolites in the geological structure of Cuba. Geotectonics, 23(4): 332-341.

Iturralde-Vinent, M.A. 1994. Cuban geology: A new plate tectonic synthesis. Journal of Petroleum Geology, 17(1): 39-70.

Iturralde-Vinent, M.A. 1996. Geología de las ofiolitas de Cuba. En: Iturralde-Vinent, M.A. (Ed.). Ofiolitas y arcos volcánicos de Cuba. First Contribution IGCP Project 364, Miami, pp. 83-120.

Iturralde-Vinent, M.A. 1998. Sinopsis de la constitución geológica de Cuba. Acta Geológica Hispánica, 33(14): 9-56.

Iturralde-Vinent, M.A., García-Casco, A., RojasAgramonte, Y., Proenza, J.A., Murphy, J.B., and Stern, R.J. 2016. The geology of Cuba: A brief overview and synthesis. GSA Today, 26(10): 4-10.

James, K.H. 2006. Arguments for and against the Pacific origin of the Caribbean Plate: Discussion, finding for an inter-American origin. Geologica Acta, 4(1-2): 279-302. 
James, K.H. 2009. In situ origin of the Caribbean: Discussion of data. In: James, K.H., Lorente, M.A., and Pindell, J.L. (Eds). The Origin and evolution of the Caribbean Plate. The Geological Society of London, pp. 77-125.

Kerr, A.C., Iturralde-Vinent, M.A., Saunders, A.D., Babbs, T.L., and Tarney, J. 1999. A new plate tectonic model of the Caribbean: Implications from a geochemical reconnaissance of Cuban Mesozoic volcanic rocks. Geological Society of America, Bulletin, 111(11): 1581-1599.

Lapierre, H., Dupuis, V., Mercier de Lépinay, B., Tardy, M., Ruíz, J., Maury, R., Hernández, J., and Loubet, M. 1997. Is the lower Duarte igneous complex (Hispaniola) a remanent of the Caribbean plume-generated oceanic plateau?. The Journal of Geology, 105(1): 111-120.

Lázaro-Calisalvo, C. 2004. Caracterización litológica y geoquímica de la malange de la Sierra del Convento, E Cuba. Trabajo de Investigación. Universidad de Granada (España): 86 pp.

Lázaro, C., García-Casco, A., Blanco-Quintero, I.F., Rojas-Agramonte, Y., Corsini, M., and Proenza, J.A. 2015. Did the Turonian-Coniacian plume pulse trigger subduction initiation in the Northern Caribbean? Constraints from ${ }^{40} \mathrm{Ar} /{ }^{39} \mathrm{Ar}$ dating of the Moa-Baracoa metamorphic sole (eastern Cuba). International Geology Review, 57(5-8): 919-942.

Lundgren, P., and Russo, R. 1996. Finite element modeling of crustal deformation in the North AmericaCaribbean Plate Boundary Zone. Journal of Geophysical, 101(B5): 11317-11327.

Magnier, C., Moretti, I., López, J.O., Gaumet, F., López, J.G., and Letouzey, J. 2004. Geochemical characterization of source rocks, crude oils, and gases of Northwest Cuba. Marine and Petroleum Geology, 21(2): 195-214.

Mann, P. 1999. Caribbean sedimentary basins: Classification and tectonic setting. In: Mann, P. (Ed.). Sedimentary basins of the World. Elsevier Science. Amsterdam, 4: pp. 3-31.

Marchesi, C., Garrido, C.J., Bosch, D., Proenza, J.A., Gervilla, F., Monié, P., and Rodríguez-Vega, A. 2007. Geochemistry of Cretaceous magmatism in Eastern Cuba: Recycling of North American continental sediments and implications for subduction polarity in the Greater Antilles paleo-arc. Journal of Petrology, 48(9): 1813-1840.

Meschede, M., and Frisch, W. 1998. A plate-tectonic model for the Mesozoic and Early Cenozoic history of the Caribbean plate. Tectonophysics, 296(3-4): 269-291.

Millán, G. 1996. Metamorfitas de la asociación ofiolítica de Cuba. In Ofiolitas y Arcos Volcánicos de Cuba. In: Iturralde-Vinent, M.A. (Ed.). IGCP Project 364. Special Contribution 1. Miami, USA. pp. 147-153.

Petford, N., and McCaffrey, K.J.W. 2003. Hydrocarbons in crystalline rocks. Geological Society of London. London, Vol. 214: 250p.

Pindell, J.L, and Dewey, J.F. 1982. Permo-Triassic reconstruction of western Pangea and the evolution of the Gulf of Mexico-Caribbean region. Tectonics, 1(2): 179-211.

Pindell, J.L., and Barrett, S.F. 1990. Geological evolution of the Caribbean region: A plate-tectonic perspective. In: Dengo, G., and Case, J.E. (Eds.). The Caribbean Region. vol. H. Geological Society of America. Boulder, pp. 339-374.

Pindell, J.L. 1994. Evolution of the Gulf of Mexico and the Caribbean. In: Donovan, S.K., and Jackson, T.A. (Eds.). Caribbean geology: An introduction. University of the West Indies Publishers' Association, Kingston, pp. 13-39.

Proenza, J.A. 1998. Mineralizaciones de cromita en la Faja Ofiolítica Mayarí-Baracoa, Cuba: Ejemplo del yacimiento Merceditas. Tesis Doctoral, Universidad de Barcelona, España. 227p.

Proenza, J.A., Díaz-Martínez, R., Iriondo, A., Marchesi, C., Melgarejo, J.C., Gervilla, F., Garrido, C.J., Rodríguez-Vega, A., Lozano-Santacruz, R., and BlancoMoreno, J.A. 2006. Primitive Cretaceous island-arc volcanic rocks in eastern Cuba: The Téneme Formation. Geologica Acta, 4(1-2): 103-121.

Pszczolkowski, A. 1999. The exposed passive margin of North America in Western Cuba. In: Mann, P. (Ed.). Sedimentary basins of the World. Elsevier Science, Amsterdam, 4: pp. 93-121.

Ross, M.I., and Scotese, C.R. 1988. A hierarchical tectonic model of the Gulf of Mexico and Caribbean region. Tectonophysics, 155(1-4): 139-168. 
Rossello, E.A., López de Luchi, M.G., Malone, P., and Fantin, F.A. 1999. Age and tectonic significance of the Puerto Lucia gabbro (Santa Elena Península, Ecuador). II South American Symposium on Isotope Geology, Villa Carlos Paz, Argentina, pp. 349-353.

Rossello, E.A., Cobbold, P.R., Diraison, M., and Arnaud, N. 2002. Auca Mahuida (Neuquén Basin, Argentina): a Quaternary shield volcano on a hydrocarbon-producing substrate. V International Symposium on Andean Geodynamics, Toulouse, France, pp. 549-552.

Schenk, C.J. 2008. Jurassic-Cretaceous Composite Total Petroleum System and geologic models for oil and gas assessment of the North Cuba Basin, Cuba. In: U.S. Geological Survey North Cuba Basin Assessment Team. Jurassic-Cretaceous composite total petroleum system and geologic assessment of oil and gas resources of the North Cuba Basin, Cuba. U.S. Geological Survey Digital Data Series DDS-69-M, chap. 2: 94 pp.

Schenk, C.J., Ahlbrandt, T.S., Charpentier, R.R., Henry, M.E., Klett, T.R., Pollastro, R.M., y Weaver, J.N. 2005. Evaluación de los recursos potenciales de petróleo y gas en la Cuenca Norte de Cuba, Cuba, 2004. Hoja Informativa de la Evaluación Mundial de Petróleo y Gas. U.S. Department of the Interior, U.S. Geological Survey, Fact Sheet 2005-3009.

Sosa-Meizoso, C., y López-Riviera, J.G. 2007. Evolución de la cuenca del margen continental para la región que ocupa la Sierra del Rosario. VII Congreso de Geología y Minería, 2da. Convención Cubana de Ciencias de la Tierra, Geociencias. La Habana.

Stephan, J.F., Mercier de Lepinay, B., Calais, E., Tardy, M., Beck, C., Carfantan, J.C., Olivet, J.L., Vila, J.M., Bouysse, P., Mauffret, A., Bourgois, J., Thery, J.M., Tournon, J., Blanchet, R., and Dercourt, J. 1990. Paleogeodynamic maps of the Caribbean: 14 steps from Lias to Present. Societé Géologique de France, Bulletin, VI(6): 915-919.

Sykes, L.R., McCann, W.R., and Kafka, A.L. 1982. Motion of Caribbean plate during last 7 million years and implications for earlier Cenozoic movements. Journal of Geophysical Research, 87(B13): 1065610676.

Sylvester, A.G. 1988. Strike-slip faults. Geological Society of America, Bulletin, 100(11): 1666-1703.

Valladares, S. 1985. Metodología para la evaluación de los colectores y sus propiedades de las rocas pertenecientes al complejo alóctono Eugeosinclinal. Tesis Doctoral, Universidad de La Habana, La Habana. 150p.

Valladares-Amaro, S., Echevarría-Rodríguez, G., Gómez-Herrera, J., y Álvarez-Castro, J. 1996. Las ofiolitas de Cuba, un caso interesante en la producción petrolera mundial. AAPG International Conference and Exhibition, Caracas, Venezuela.

Trabajo recibido: julio 11 de 2017

Trabajo aceptado: agosto 02 de 2017 